ARTICLE INFO

Received

February 09, 2020

Revised

April 20, 2020

Accepted

April 22, 2020

Published

June 05, 2020

*Corresponding author

Olugbenga Samson Abe

E-mail

abeolugbenga@gmail.com

Phone

08138083808

Keywords

Body weight

Crossbreeding

Feed intake

Fertility

Chicken genotype

How to cite

Amusan SA, Abe OS, Fasola

HO, Adedeji TA. Egg

hatchability and growth

performance of cross and

backcross involving Nigeria

Fulani ecotype and Isa brown

chickens. Sci Lett 2020;

$8(2): 87-92$
Open Access

\section{Egg Hatchability and Early Growth Performance of Cross and Backcross Involving Nigeria Fulani Ecotype and Isa Brown Chickens}

\author{
Samuel Ayotunde Amusan ${ }^{1}$, Olugbenga Samson Abe*2, Helen \\ Omosalewa Fasola ${ }^{3}$, Tosin Ademola Adedeji ${ }^{3}$ \\ ${ }^{1}$ Department of Animal Production, Federal College of Animal Health and Production, \\ Moor Plantation, Ibadan, Nigeria \\ ${ }^{2}$ Department of Animal Science, Adekunle Ajasin University, Akungba-Akoko, Nigeria \\ ${ }^{3}$ Department of Animal Production and Health, Ladoke Akintola University of \\ Technology, Ogbomoso, Nigeria
}

\section{Abstract}

An experiment was carried out to study the egg hatchability and growth performance of crossbred chickens involving Fulani ecotype (E) and Isa brown (B) chickens and their backcross using artificial insemination method of mating. The F1 progeny, the crossbred (EB), was produced by crossing E (sire) with B (dam) while the first backcross (BEB) was achieved using the $\mathrm{B}$ (sire) and the EB (dam). The second backcross (EBB) was carried out by mating the EB (sire) and the B (dam). A total of 35 birds were used as foundation stock (five E males, five B males and $25 \mathrm{~B}$ female chickens) to produce 137 EB crossbred chickens and 187 backcross chickens (98 EEB chickens and 89 BEB chickens). Weekly body weight and daily feed intake were obtained on the progenies generated from the mating for a period of 20 weeks. Other parameters like weight gain, feed conversion ratio, percentage fertility, hatchability and percentage dead shell were calculated from the data. The results revealed that the growth performance was affected by genotype. The EB chickens obtained the highest body weight across the weeks ( 37.6 to $1169 \mathrm{~g}$ ) and the backcross chickens had the highest fertility (76.2\%) and hatchability (83.2\%). Therefore, it could be concluded that crosses between the Fulani ecotype and Isa brown chickens had the best growth performance and improved fertility while the backcross sired by the F1 had better performance when hatchability is considered. 


\section{Introduction}

In Africa, agriculture and agro-industries account for more than $30 \%$ of national incomes on average, as well as for the bulk of export revenues [1]. While nearly three-quarters of the population depend on the livestock and crops to secure their livelihoods [2]. In Nigeria; however, the poultry industry, which consists of chickens, turkeys, ducks and pigeons is the largest industry amongst the agroindustries. The Nigerian poultry industry has been rapidly expanding in recent years and is, therefore, one of the most commercialized subsectors of Nigerian agriculture [3]. Poultry production has both social and cultural benefits and it plays a significant part in family nutrition in most developing countries. Poultry production is unique because it offers the highest turnover rate and the quickest return on investment outlay in livestock enterprises [4]. Of the 120 million poultry birds found in Nigeria, the native chicken constitutes about $80 \%$ of the population [5]. The Nigerian native chickens have been confirmed as a veritable tool for the genetic improvement and development of layer strain for the tropical environment because they possess some inherent advantages, including good fertility and hatchability, the better flavor of meat and egg, high degree of adaptability, high genetic variance in their performance, hardness, disease tolerance, ease of rearing, high genetic variance in their performance and ability to breed naturally $[6,7]$. It has been reported by researchers that the main problem of indigenous chickens in the tropics is that they are poor producers of egg and meat [8]. On the other hand, exotic chickens, which have undergone genetic improvement for better performance in terms of faster growth, higher number of eggs and more meat than the unimproved indigenous chicken breeds rarely exhibit good repeatability in the tropics. The tropical climate is; however, a huge challenge to these exotic breeds to fully express their genetic potential because they are not adapted to the adverse tropical environmental condition like high temperature, disease occurrence and shortage of feed [9].

Fertility, hatchability, egg production and growth are economically important traits in local poultry production systems, and breeders usually aimed at conserving and increasing the productive genetic efficiency of native chickens through crossbreeding for higher economic gains [10]. High fertility and hatchability of breeder stock and survivability of the chicks are necessary to produce a large number of birds. This would augment the grossly inadequate protein supply of developing countries like Nigeria [11]. In order to exploit the improved traits in the exotic and the adaptability features in the indigenous chickens, crossing of the local stock with an exotic commercial breed could take advantage of artificial selection for productivity in the exotic birds and natural selection for hardiness in the indigenous birds [12]. Furthermore, backcrossing is a well-known and long-established breeding method where a trait of interest is introgressed from a donor parent into the genomics background of a recurrent parent. Because backcrossing can isolate a gene or chromosomal region in a different genetic background, it helps to discern the genetic architecture of qualitative traits [13]. Moreover, birds with better production performance can equal the combining ability of best performing exotic lines and indigenous chicken. Therefore, this study aimed at comparing the egg hatchability and early growth performance of the progenies resulting from crossbreeding of Nigeria Fulani ecotype and Isa brown chicken and their backcrosses.

\section{Materials and Methods}

\section{Experimental site}

The experiment was carried out in the poultry unit of Teaching and Research Farm, Ladoke Akintola University of Technology, Ogbomoso, Oyo State, Nigeria. The site is located in the derived savannah zone of Nigeria on longitude $4^{0} 15^{`}$ East and latitude

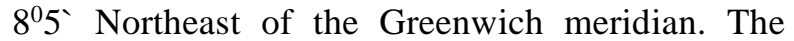
altitude is between $300 \mathrm{~m}$ and $600 \mathrm{~m}$ above sea level. The mean annual rainfall and temperature are $1247 \mathrm{~mm}$ and $27^{\circ} \mathrm{C}$, respectively.

\section{Mating procedure}

The hens were artificially inseminated with semen obtained from the male chickens. The semen samples were collected through the massage technique by applying slight pressure at the back of the male chicken towards the tail. Feathers around the vent of the male chickens were shaved regularly for ease of semen collection and also to prevent contamination. The semen samples were used immediately after collection by applying $0.1 \mathrm{ml}$ of the undiluted semen to the cloaca of each hen once a week. The Fulani ecotype was used as the parent sire breed to mate Isa brown female birds. The breeding model is written as Sire before Dam (i.e., $\mathrm{SD})$. Mating procedures are given below: 
Fulani ecotype $(\mathrm{E})$ sire $\times$ Isa brown $(\mathrm{B})$ dam $=\mathrm{E} \times$ $\mathrm{B}=\mathrm{F}_{1}(\mathrm{~EB})$

First backcross sire by Isa brown $(\mathrm{B}) \times \mathrm{F} 1$ dam (EB) $=\mathrm{B} \times \mathrm{EB}=\mathrm{BEB}$

Second backcross sire by $F_{1}$ dam $(E B) \times$ Isa brown $\operatorname{dam}(\mathrm{B})=\mathrm{EB} \times \mathrm{B}=\mathrm{EBB}$

\section{Experimental birds}

A total of ten (10) sires and twenty-five (25) dams were used as foundation stock for the study. The foundation stock; however, included 5 Fulani ecotype (E) sire, 5 Isa brown (B) sire and twentyfive (25) Isa brown (B) dam. The foundation stock was fed breeder mash. The resulting F1 chickens and the backcross were fed ad-libitum with chick mash from day 1 to 4 weeks and growers mash from 4 weeks till the point of lay (18 weeks) and thereafter with layers mash for 4 weeks and then breeder mash for the rest of the experiment. The ingredient composition of the various diets is presented in Table 1.

\section{Egg collection and incubation}

The eggs were collected along the genotype line and stored in a cool room with an ambient temperature of $18-20^{\circ} \mathrm{C}$ before transferring to the hatchery for incubation. The incubator was set at the temperature between $27-39^{\circ} \mathrm{C}$ and relative humidity of $55-66 \%$ for the first eighteen days. The temperature was subsequently increased to $29^{\circ} \mathrm{C}$ and $35^{\circ} \mathrm{C}$ with the relative humidity of $70-75 \%$ for the last three days. Candling was carried out on the $3^{\text {rd }}$ and $18^{\text {th }}$ day of incubation for the identification of clear and fertile eggs. After hatching, the number of normal, weak, abnormal and dead chicks were recorded.

\section{Management of chicks}

All chicks resulting from each genotype were properly identified and wing tagged along sire lines and were placed separately in a brooding pen. Every hatch was brooded for a period of four weeks using a brooding guard within a pen house. Burning charcoal was provided to generate heat and maintain an ambient temperature of $27^{\circ} \mathrm{C}$ for the birds from a day old to 2 weeks of age. The birds were fed with commercial chicken mash ad-libitum till 4 weeks of age and water was given freely. Medication and vaccination were done as and when needed.

\section{Data collection and statistical analysis}

Bodyweight data and feed intake were obtained on the progenies generated from the mating for a period of 20 weeks. Weekly body weight was measured with the use of $0.01 \mathrm{~g}$ sensitive scale while the average feed intake was calculated as the difference between left overfeed and feed given, divided by the total number of birds. The daily weight gain represented the difference between two consecutive measurements divided by the number of days. The feed conversion ratio (FCR) was calculated as the ratio of feed intake to weight gain within each measurement period. The progenies were allowed to lay two weeks before insemination and another one week to lay after insemination before the start of egg collection. The following data were recorded on hatchability: the number of egg set, which represents the number of eggs taken to the hatchery; percentage fertility, which was calculated as the percentage of eggs that were fertile out of all the egg set; hatchability was calculated

Table 1 Chemical composition of various diets used to feed mating chickens.

\begin{tabular}{lcccc}
\hline Ingredients & Chick mash & Grower mash & Layer mash & Breeder mash \\
\hline Maize (\%) & 47.00 & 37.00 & 36.00 & 50.00 \\
Maize bran (\%) & 5.00 & 12.00 & 17.20 & 15.00 \\
Wheat offal (\%) & 17.25 & 23.00 & 20.00 & 8.00 \\
GNC (\%) & 2.00 & 8.00 & - & - \\
Soya bean (\%) & 22.00 & 6.00 & 14.00 & 16.50 \\
Palm kernel cake (\%) & - & 9.75 & - & - \\
Fish meal (72\%) & 3.50 & 1.00 & 1.00 & 1.50 \\
Bone meal (\%) & 1.00 & 1.00 & 2.00 & 1.00 \\
Oyster shell (\%) & 1.00 & 1.00 & 0.50 & 7.05 \\
Methionine (\%) & 0.25 & 0.25 & 0.25 & 0.20 \\
Lysine (\%) & 0.25 & 0.25 & 0.50 & 0.25 \\
Premix (\%) & 0.50 & 0.50 & 0.25 & 0.25 \\
Salt $(\%)$ & 0.25 & 0.25 & 16.80 & 0.25 \\
Crude protein (\%) & 20.50 & 15.00 & 2580 & 17.50 \\
Gross energy (kcal/kg) & 2650 & 2500 & & 2700 \\
\hline
\end{tabular}


as the percentage of egg hatched out of all the fertile egg set; the percent dead shell was calculated as unhatched eggs. The data were analyzed using ANOVA and the means were separated using Duncan multiple range test. The statistical analysis system (SAS), version 9.2, SAS Institute Inc. Cary, NC, USA was used for statistical analysis.

\section{Results}

The absolute values and the percentage of egg set, fertility and hatchability estimates in different chicken genotypes are presented in Table 2 . Relative to the number of egg sets for all the genotypes, the highest percentage of the fertile egg was obtained in EB $(75 \%)$ followed closely by EBB (74\%) and BEB (73\%). The percentage of hatchability was highest in EBB (81.5\%) while the other two genotypes (EB and BEB) had similar values $(75 \%)$. This close variation may be due to the number of egg sets. The highest percentage of the dead in the shell was recorded in EB (25\%).

Table 2 Absolute values and percentage of egg set, fertility and hatchability estimates in different chicken genotypes.

\begin{tabular}{lllll}
\hline \multirow{2}{*}{ Parameters } & \multirow{2}{*}{$\mathbf{N}$} & \multicolumn{3}{c}{ Genotype } \\
\cline { 3 - 5 } & & EB & BEB & EBB \\
\hline Egg set & 400 & 128 & 126 & 146 \\
Fertile egg & 292 & $96(75 \%)$ & $92(73 \%)$ & $108(74 \%)$ \\
Infertile egg & 108 & $32(25 \%)$ & $34(27 \%)$ & $38(26 \%)$ \\
Hatched egg & 216 & $72(75 \%)$ & $69(75 \%)$ & $88(81.5 \%)$ \\
Dead in shell & 76 & $24(25 \%)$ & $23(25 \%)$ & $2018.5 \%)$ \\
\hline N = number of observations \\
EB = Fulani ecotype (E) $\times$ Isa brown (B); BEB = B $\times \mathrm{EB} ; \mathrm{EBB}=\mathrm{EB} \times \mathrm{B}$
\end{tabular}

The mean body weight and feed efficiency at different ages of different chicken genotypes are presented in Table 3. The initial body weight of one-day-old chickens (37.6 g) was highest in the crossbred EB followed by BEB. The body weight at 4 weeks showed a similar trend observed for one day old EB having the highest value of $195 \mathrm{~g}$ followed by BEB (163.4 g) while EBB had the lowest body weight $(157.7 \mathrm{~g})$. Moreover, at 4 weeks, the feed intake $(28.2 \mathrm{~g})$ and body weight gain $(6.27 \mathrm{~g})$ were highest in BEB, while the feed conversion ratio was non-significantly different between EB and BEB and EBB showed the lowest feed conversion ratio. At 8 weeks, crossbreed EB (4.45) had the highest feed conversion ratio though with second best feed intake still ended up with the highest body weight of 511.7 g. BEB consumed more feed $(40.3 \mathrm{~g})$ but did not gain weight as much as the crossbred EB (511.7 g), which consumed lesser feed $(35.4 \mathrm{~g})$. At the twelfth week, EB and EBB consuming more feed $(60.5 \mathrm{~g}$ and $61.6 \mathrm{~g}$, respectively); however, EBB had the highest feed conversion ratio (18.30) and lowest body weight $(643.4 \mathrm{~g})$ despite having the highest feed intake. From the result of $16^{\text {th }}$ week, the crossbred EB had a higher body weight (1169 g) and body weight gain $(18.5 \mathrm{~g})$ with the least feed conversion ratio (5.15). EBB had the highest feed intake of $99.3 \mathrm{~g}$ and the highest feed conversion ratio of 18.2 with the lowest body weight of $844.6 \mathrm{~g}$. The backcross BEB overtook the crossbred EB at the 20 weeks in body weight $(1480.5 \mathrm{~g})$ and with a superior feed conversion ratio of 8.87 .

\section{Discussion}

Three genotypes were considered for hatchability and growth performance. From the result of the present study, little variations were observed among the genotypes with respect to fertility, although the F1 crossbred EB had the highest fertility followed by the F1 sired backcross (EBB) and those sired by Isa brown (BEB). This may be due to variation in the genetic makeup of the different genotypes because all the genotypes were subjected to a similar management routine. Nwakpu et al. [6] in their study also observed significant differences in the fertility percentages among three genotypes of layer-type chickens. They observed that the black Olympia and Hubbard and Nick strains were higher in egg fertility than the investigated Nigerian local chicken. The backcross EBB sired by the F1 genotype had the highest hatchability percentage compared to the F1 crossbred and the Isa brown sired backcross BEB. This shows that the injection of genes from the Isa brown chickens on the backcross mating to the F1 genotype did not have any improvement on the hatchability of the genotype when compared to the impact of F1 genes backcrossed to Isa brown chickens where the hatchability was improved by $6.5 \%$ over other genotypes. This further shows that the addition of Fulani ecotype genes in a proportion of $25 \%$ may be good in the development of layer strain towards improving egg hatchability. However, the high hatchability reported in the present study along the inclusion of Fulani ecotype in the breeding of the backcross genotype was higher than $48 \%$ compared to the hatchability reported by Fayeye et al. [5] in their study with Fulani ecotype where they opined that it was not uncommon and may not be due to genetic factors. 
Table 3 Mean and standard error of mean for body weight and feed efficiency at different ages for the different chicken genotypes.

\begin{tabular}{|c|c|c|c|c|c|}
\hline Genotype & $\mathbf{N}$ & BW (g) & FI & BWG (g) & FCR \\
\hline \multicolumn{6}{|l|}{1 day old } \\
\hline EB & 72 & $37.56 \pm 1.69 a$ & NA & NA & NA \\
\hline BEB & 69 & $34.92 \pm 0.54 b$ & NA & NA & NA \\
\hline EBB & 88 & $33.17 \pm 0.05 c$ & $\mathrm{NA}$ & NA & NA \\
\hline \multicolumn{6}{|l|}{4 weeks } \\
\hline EB & 71 & $195.00 \pm 8.75 \mathrm{a}$ & $23.27 \pm 6.00 \mathrm{~b}$ & $5.27 \pm 0.02 b$ & $4.42 \pm 0.02 \mathrm{a}$ \\
\hline BEB & 67 & $163.44 \pm 4.62 b$ & $28.29 \pm 8.27 \mathrm{a}$ & $6.27 \pm 0.03 a$ & $4.51 \pm 0.02 \mathrm{a}$ \\
\hline EBB & 87 & $157.71 \pm 6.20 \mathrm{c}$ & $17.17 \pm 2.40 \mathrm{c}$ & $4.70 \pm 0.02 c$ & $3.65 \pm 0.12 b$ \\
\hline \multicolumn{6}{|l|}{8 weeks } \\
\hline EB & 71 & $511.67 \pm 27.61 \mathrm{a}$ & $35.44 \pm 3.20 c$ & $7.90 \pm 0.02 c$ & $4.50 \pm 0.03 \mathrm{a}$ \\
\hline BEB & 66 & $443.64 \pm 12.44 b$ & $40.27 \pm 5.23 a$ & $11.62 \pm 0.03 b$ & $4.33 \pm 0.02 \mathrm{a}$ \\
\hline EBB & 87 & $421.62 \pm 22.69 b$ & $31.56 \pm 6.01 b$ & $15.90 \pm 0.04 a$ & $3.97 \pm 0.01 b$ \\
\hline \multicolumn{6}{|l|}{12 weeks } \\
\hline $\mathrm{EB}$ & 71 & $830.00 \pm 35.98 \mathrm{a}$ & $60.46 \pm 10.24 b$ & $22.10 \pm 2.51 \mathrm{a}$ & $3.80 \pm 2.10 b$ \\
\hline BEB & 64 & $795.56 \pm 23.06 b$ & $56.63 \pm 8.23 c$ & $12.30 \pm 6.04 b$ & $4.60 \pm 2.40 b$ \\
\hline EBB & 85 & $643.38 \pm 53.45 \mathrm{c}$ & $61.56 \pm 8.01 \mathrm{a}$ & $3.47 \pm 2.40 \mathrm{c}$ & $18.30 \pm 3.10 \mathrm{a}$ \\
\hline \multicolumn{6}{|l|}{16 weeks } \\
\hline EB & 67 & $1169.00 \pm 25.31 \mathrm{a}$ & $95.24 \pm 2.43 b$ & $18.50 \pm 4.20 \mathrm{a}$ & $5.15 \pm 0.02 b$ \\
\hline BEB & 64 & $1124.11 \pm 35.03 b$ & $91.59 \pm 9.26 c$ & $12.44 \pm 4.28 b$ & $7.36 \pm 0.03 b$ \\
\hline EBB & 84 & $844.60 \pm 66.13 c$ & $99.29 \pm 2.50 \mathrm{a}$ & $2.60 \pm 0.02 c$ & $18.20 \pm 4.28 \mathrm{a}$ \\
\hline \multicolumn{6}{|l|}{20 weeks } \\
\hline $\mathrm{EB}$ & 65 & $1440.89 \pm 44.47 b$ & $118.18 \pm 8.11 \mathrm{a}$ & $6.55 \pm 2.10 c$ & $18.04 \pm 2.75 \mathrm{a}$ \\
\hline BEB & 63 & $1480.45 \pm 48.07 \mathrm{a}$ & $90.66 \pm 9.23 b$ & $10.22 \pm 2.40 b$ & $8.87 \pm 0.30 b$ \\
\hline EBB & 84 & $1154.46 \pm 67.07 \mathrm{c}$ & $64.81 \pm 6.42 c$ & $27.33 \pm 2.51 \mathrm{a}$ & $2.37 \pm 0.02 c$ \\
\hline
\end{tabular}

Values having different letters along column for a given trait differ significantly $(P<0.05)$.

$\mathrm{N}=$ number of observations; $\mathrm{BW}=$ body weight; $\mathrm{FI}=$ feed Intake; $\mathrm{BWG}=$ body weight gain; $\mathrm{FCR}=$ feed conversion ratio; $\mathrm{NA}=$ not applicable

$\mathrm{EB}=$ Fulani ecotype $(\mathrm{E}) \times$ Isa brown $(\mathrm{B}) ; \mathrm{BEB}=\mathrm{B} \times \mathrm{EB} ; \mathrm{EBB}=\mathrm{EB} \times \mathrm{B}$

The pattern of growth with respect to bodyweight recorded in the present study supported the fact that the initial weight of most livestock at birth is a determinant of the pattern of subsequent rate of growth. Meijerhof [14] stated that the weight of a day-old chicks can be used as an indicator of subsequent chick development. Furthermore, the superiority of the crossbred over the backcross chicken could be attributed to the additive and nonadditive gene effects of crossbreeding. Johnson et al. [15] in their study reported that the crossing of different breeds allows the farmer to make use of additive and non-additive genetic differences among the breeds to increase production.

\section{Conclusion}

The study showed that there were notable differences among the genotypes with respect to fertility, hatchability and weight gain. The backcross to Isa brown chickens sired by F1 crossbred performed better in relation to fertility and weight gain while hatchability was an element of Fulani ecotype in the mating model as a sire breed. It could then be concluded that Fulani ecotype genes should be used as a sire breed for crosses involving Isa brown for better fertility, hatchability and growth.

\section{Conflict of Interest}

The author declares no conflict of interest in this study.

\section{References}

[1] Heinke H, Alexandra C, Ludwig T. The poultry market in Nigeria: market structures and potential for investment in the market. Int Food Agribus Man Rev 2015; 18 special issue:197-222.

[2] Connolly AJ. A glimpse into the future: A lens through which to consider Africa's rising. International Food and Agribusines Management Review 17(Special Issue B) $2014 ; 9-18$.

[3] Adene DF, Oguntade AE. The structure and the importance of the commercial and village-based poultry systems in Nigeria. FAO; 2006.

[4] Ogundipe SO, Sanni SA. Economic of poultry production in Nigeria. A training manual on National Training Workshop on Poultry Production in Nigeria. National Institute for Animal Production Research Institute (NAPRI), Ahmadu Bello University, Zaria, 2002; pp. 27-45

[5] Fayeye TR, Adeshiyan AB, Olugbami AA. Egg traits, hatchability and early growth performance of the 
Fulani-ecotype chicken. Livest Res Rural Develop 2005; 17(8):94.

[6] Nwakpu PE, Odo BI, Omeje SS, Akpan GN, Edoga CC. Hatching performance of three strains of layer type of chicken and their lines. Proceedings of $26^{\text {th }}$ NSAP Conference $23^{\text {rd }}-26^{\text {th }}$ March, Ilorin Kwara State, Nigeria; 1999, pp. 25-29.

[7] Adedeji, TA, Ojedapo, LO, Ige AO, Ameen SA, Akinwunmi AO, Amao SR. Genetic evaluation of growth performance of pure and crossbred chicken progenies in a derived savannah environment. Proceedings of the $13^{\text {th }}$ Annual Conference of the Animal Science Association of Nigeria (ASAN), September 15-19, Abu Zaria, Nigeria; 2008, pp. 8-12.

[8] Tadelle D, Alemu Y, Peters KJ. Indigenous chicken in Ethiopia: Genetic potential and attempt at improvement. Poult Sci 2000; 56:45-54.

[9] Islam M A, Nishibori M. Indigenous naked neck chickens: A valuable genetic resources for Bangladesh.
World Poultry Science Journal 2009; 65:125-138.

[10] Abou El-Ghar RS. Estimation of genetic and phenotypic parameters in $3^{\text {rd }}$ generation and backcross of some local strains. Egypt Poult Sci 2014; 34(2):521535.

[11] NseAbasi NE, Joseph SE, Glory EE. Dietary influence of Aspilia Africana on litter traits of breeding female rabbits. Am J Exp Agric 2014; 4(2):153-156.

[12] Adebambo OA, Ikeobi CO, Ozoje MO. Variation in growth performance of pure and crossbred meat type chickens. Niger J Anim Prod 2009; 36(2):211-227.

[13] Hospital F. Selection in backcross program. Philos Trans R Soc B 2005; 360:1503-1511.

[14] Meijerhof R. What count for chick quality? Hybro BV May. Poult Sci 2005; 22:30-31.

[15] Johnson DJ, Thompson JM, Hammond K. Additive and non-additive difference in milk production of 2-year old Devon heifer and reciprocal crossed heifer. Livest Prod Sci 1995; 41:105-110. 